\title{
Optimization of Electrical Discharge Coating Process by Desirability Function approach
}

\author{
Sarat Kumar Sahoo ${ }^{1}$, Pathalavathi Bhaskar ${ }^{2}$ \\ ${ }^{1}$ Asst. Prof., CVR College of Engineering / Mechanical Engg. Department, Hyderabad, India \\ Email: saratkumar222@gmail.com \\ ${ }^{2}$ Asst. Prof., CVR College of Engineering / Mechanical Engg. Department, Hyderabad, India \\ Email: bhaskarnaik459@gmail.com
}

\begin{abstract}
Optimization is used to obtain a higher value of output with a lower value of the input. To attain high quality with low cost in the manufacture process, the optimization of method factors is required. In this work process factors of electrical discharge coating (EDC) process are optimized by using desirability function approach (DFA), a multi-objective optimization technique used in optimization multiple output responses at a time. ANOVA table and response table are also calculated to show the importance of individual parameters.
\end{abstract}

\section{Index Terms: Optimization, EDM, Desirability, Taguchi}

\section{INTRODUCTION}

The coating is the process of applying hard and wear resistance layer material on the workpiece to improve its wear and corrosion resistance. Recently, a different composite coating of materials is used in a variety of applications like automobile, aerospace, die making industries which required coating on the used materials to increase its wear and corrosion resistance. Electro-discharge coating (EDC) is performed by the electric discharge machining process where deposition of material occurs on the surface of workpiece. A large number of processes have been used for EDC for surface reform, by using tool made up of powder metallurgy and surface modification tool by using composite electrodes. In the EDC process tool electrode made by powder metallurgy process is used by Sahu et al. (2018) [1]. Patowari et al. (2011) and Patowari et al. (2015) have used $\mathrm{Cu}-\mathrm{W}$ composite tool during EDC process on C-40 steel workpiece [2,3]. Ahmad (2016) has used Ti-B ${ }_{4} \mathrm{C}$ tool during EDC on Aluminum workpiece [3]. Sahu et al. (2018) have optimized the EDC process by VIKOR based Harmony search algorithm [4]. Again Sahu and Mahapatra (2018) have used the GRA based Harmony search algorithm for optimization of the EDC process [5]. In this present study, desirability function approach (DFA) has been used for multi-criteria optimization of the EDC process.

\section{A. Optimization}

Optimization is generally used to solve any engineering problem. The importance of optimization in different engineering fields are listed below; Effective utilization of input resources, Maximization of benefits and Minimization of cost in various manufacturing and construction, Optimal production planning, controlling and scheduling, peak allocation of assets or facilities among numerous activities, preparation of maintenance and equipment replacement to decrease operational cost, Inventory mechanism, selection of manufacturing condition in metal cutting method to minimize manufacture cost, improvement of industry productivity. [6]

Maximization of output in terms of quality and quantity of the process with minimization of input in terms of material and cost is the basic target of every manufacturing industry. The EDM technique is a combination of number of factors like electro-dynamics, electro-magnetic, thermo-dynamic and hydro-dynamic activities, which unveils a complex nature of the process performance. A number of factors (namely; workpiece material, electrode, dielectric medium, pulse on \& off time, voltage, current, Flushing pressure, etc.) influence its performance characteristics. Change in a single parameter will affect the practice in a complex way. The EDM companies and customers always try to attain higher productivity with a required accuracy and surface finish. Therefore, it is essential for optimization WEDM process parameters.

On the basis of requirements, optimization can be classified into two types; Design Optimization \& Process Optimization. On the basis of versatility, optimization can also be divided into two types; single response optimization and multi-response optimization technique. Multi-response optimization is used to optimize more than one output parameter simultaneously. In this present study desirability function technique is applied for optimization of the process parameters.

\section{B. Desirability function approach (DFA)}

The desirability function methodology is a multiple response optimization technique, which is mostly used for the optimization problem in the industry. This method is based on the quality characteristics with most acceptable value, least acceptable or completely unacceptable values. This technique finds operating sequence which provide the "most desirable" response values (Bara et al. (2018) [7], Sahu and Mahapatra (2019) [8], Karande et al. (2013) [9], Singaravel and Selvaraj (2016) [10]).

$1^{\text {st }}$ Step: The individual desirability index (di) for the corresponding outputs can be calculated by using the equations (1) to (3), as per given below. According to the performance characteristics, there are 3 systems of the desirability functions

i. Nominal - the best 


$$
d_{i}=\left\{\begin{array}{c}
\left(\frac{y_{j}-y_{\min }}{T-y_{\min }}\right)^{s}, y_{\min } \leq y_{j} \leq T, s \geq 0 \\
\left(\frac{y_{j}-y_{\min }}{T-y_{\min }}\right)^{s}, T \leq y_{j} \leq y_{\max }, s \geq 0 \\
0
\end{array}\right.
$$

The value of $y_{j}$ is essential to attain a particular objective $\mathrm{T}$. When the value of ' $\mathrm{y}_{\mathrm{j}}$ ' equals to the value of $\mathrm{T}$, the desirability value becomes 1 . When the value of ' $y_{j}$ ' surpasses a specific range from the mark, the desirability value becomes 0 , that condition denotes the worst case.

\section{ii. Larger-the better}

In this case, the value of ' $y_{j}$ ' is likely to be larger is the better case. When the ' $\mathrm{y}_{\mathrm{j}}$ ' surpasses a specific criteria value, that can be observed as per the requirement, the desirability value becomes 1 . If the ' $y_{j}$ ' is smaller than a specific standard value, then that is unacceptable and the desirability value becomes 0 .

$$
d_{i}=\left\{\begin{array}{l}
0, y_{j} \leq y_{\min } \\
\left(\frac{y_{j}-y_{\min }}{y_{\max }-y_{\min }}\right)^{r}, y_{\min } \leq y_{j} \leq y_{\max }, r \geq 0 \\
1, y_{j} \geq y_{\min }
\end{array}\right.
$$

iii. Smaller-the better

$$
d_{i}=\left\{\begin{array}{c}
1, y_{j} \leq y_{\min } \\
\left(\frac{y_{j}-y_{\max }}{y_{\min }-y_{\max }}\right)^{r}, \quad y_{\min } \leq y_{j} \leq y_{\max }, r \geq 0 \\
0, y_{j} \geq y_{\min }
\end{array}\right.
$$

In this case, the value of ' $\mathrm{y}_{\mathrm{j}}$ ' is likely to be the smaller is the better criteria. When the value of ' $y_{j}$ ' is smaller than a specific standard value, the desirability value becomes 1 . If the value of ' $y_{j}$ ' surpasses a specific range value, the desirability value becomes 0 . In this current experiment, "smaller is the better" and "larger is the better" characteristics are used for calculation of the individual desirability values for minimization and or maximization of response characteristics.

$2^{\text {nd }}$ Step: For calculation of the overall desirability $\left(\mathrm{d}_{0}\right)$, all the di values are combined and forms a particular value called overall desirability $\left(\mathrm{d}_{0}\right)$ by the by using the given equation.

$$
d_{0}=\sqrt[w]{\left(d_{1}^{w 1} \times d_{2}^{w 2} \cdots \cdots d_{i}^{w i}\right)}
$$

$3^{\text {rd }}$ Step: For calculation of the ideal parameter and its level sequence, the higher $\mathrm{d}_{0}$ value is taken into consideration. On the basis of the $\mathrm{d}_{0}$ value, the parameter outcome and the optimal level for all parameters can be predicted.

\section{Analysis of variance (ANOVA)}

ANOVA table is calculated to find out the best factors. ANOVA provides the comparative significant parameters. Calculation of the total sum of square values is required to find out the relative effect of the individual parameters. ANOVA is used to calculate the percentage of involvement of each input parameter for the overall results of the experiment.

ANOVA table can be calculated by the help of the given following equations.

$$
\begin{aligned}
& S S_{\mathrm{t}}=\sum_{\mathrm{i}=1}^{\mathrm{m}}\left(\mathrm{\eta}_{\mathrm{j}}-\overline{\mathrm{\eta}}\right)^{2} \\
& S S_{\mathrm{f}}=q \times \sum_{q=1}^{q}\left(\mathrm{n}_{\mathrm{j}}-\overline{\mathrm{n}}\right)^{2} \\
& S S_{\varepsilon}=S S_{\mathrm{t}}-\sum_{q=1}^{q} S S_{f}
\end{aligned}
$$

$$
\begin{aligned}
& \text { DOF }=\text { No. of level }-1 \\
& \text { Total DOF }=\text { Total no. of expt. }-1 \\
& M S_{f}=\frac{S S_{f}}{D O F} \\
& \% \text { Contribution }=\frac{S S_{f}}{S S_{t}} \times 100
\end{aligned}
$$

These above equations are used for calculation of the ANOVA table.

\section{RESULT AND DISCUSSION}

The model used in this work is developed by Sahu and Mahapatra (2018) as a three objective function optimization process where maximization of material deposition rate (MDR) and minimization of tool wear rate (TWR) and radial under deposition (RUD) simultaneously. The input parameters which affect the output responses are (A)sintering temperature (ST), (B)compaction pressure (CP), (C)discharge current (Ip), (D)duty cycle $(\tau)$ and (E)pulse-on-time (Ton). Here, higher-is-better is used for MDR and lower-is-better is used for TWR and RUD. By following the procedure of DFA as discussed in Eqs. (1) to (4), di and do values are calculated and presented in the 
table I. By taking the do value, the ANOVA is generated by using MINITAB software and presented in table II. The ANOVA is found out with R-square value of $77.4 \%$. From the ANOVA table, it is found that sintering temperature has the highest percentage contribution of $31 \%$ towards the outputs. Similarly, compaction pressure and pulse-on-time have $\%$ contribution of $19 \%$ and $13 \%$ respectively. The diagram of percentage contribution is given in figure 1 .

The response table for the means is given in table III. The optimum level of the input parameters is marked as ' $*$ ' mark in this table. The corresponding '*' mark levels are the optimum levels like Level-2 for A, Level-1 for B, Level-2 for C, Level-1 for D and level-3 for $\mathrm{E}$. The means and interaction graphs for the do values are shown in figure 2 and figure 3 respectively. The optimum level corresponds to the higher value do in figure 2. Similarly, the signal-to-noise $(\mathrm{S} / \mathrm{N})$ ratio of the overall desirability is presented in table I. The ANOVA of the $\mathrm{S} / \mathrm{N}$ ratio is given in table IV. Similarly, the graph of ain effect plot for $\mathrm{S} / \mathrm{N}$ ratio and interaction plot for $\mathrm{S} / \mathrm{N}$ ratio are shown in Figure 4 and 5 respectively.

TABLE I.

INDIVIDUAl DESIRABILITY INDEX (DI) AND OVERALl DESIRABILITY INDEX (Do) FOR EDC PROCESS

\begin{tabular}{|c|c|c|c|c|c|}
\hline Sl. No. & Di (MDR) & Di (TWR) & $\begin{array}{c}\text { Di } \\
\text { (RUD) }\end{array}$ & do \\
\hline 1 & 0.393 & 0.411 & 0.506 & 0.434 & -7.250 \\
\hline 2 & 0.595 & 0.077 & 0.261 & 0.229 & -12.803 \\
\hline 3 & 1.000 & 0.173 & 0.661 & 0.485 & -6.285 \\
\hline 4 & 0.191 & 0.585 & 0.000 & 0.000 & -60.000 \\
\hline 5 & 0.393 & 0.450 & 0.298 & 0.375 & -8.519 \\
\hline 6 & 0.595 & 0.000 & 0.265 & 0.000 & -60.000 \\
\hline 7 & 0.000 & 0.607 & 0.004 & 0.000 & -60.000 \\
\hline 8 & 0.393 & 0.702 & 0.258 & 0.415 & -7.639 \\
\hline 9 & 0.595 & 0.435 & 0.251 & 0.403 & -7.894 \\
\hline 10 & 0.393 & 0.406 & 0.903 & 0.525 & -5.597 \\
\hline 11 & 0.393 & 0.660 & 0.902 & 0.617 & -4.194 \\
\hline 12 & 0.595 & 0.157 & 1.000 & 0.454 & -6.859 \\
\hline 13 & 0.393 & 0.614 & 0.417 & 0.466 & -6.632 \\
\hline 14 & 0.191 & 0.475 & 0.463 & 0.348 & -9.168 \\
\hline 15 & 0.393 & 0.253 & 0.769 & 0.425 & -7.432 \\
\hline 16 & 0.191 & 0.499 & 0.661 & 0.398 & -8.002 \\
\hline 17 & 0.191 & 1.000 & 0.394 & 0.423 & -7.473 \\
\hline 18 & 0.393 & 0.541 & 0.424 & 0.449 & -6.955 \\
\hline
\end{tabular}

TABLE II.

ANALYSIS OF VARIANCE FOR MEANS

\begin{tabular}{|c|c|c|c|c|c|c|}
\hline Source & DF & SS & MS & F & P & \% of Contri bution \\
\hline $\mathrm{A}$ & 1 & 0.172872 & 0.172872 & 2.72 & 0.241 & 31 \\
\hline $\mathrm{B}$ & 2 & 0.107328 & 0.053664 & 0.84 & 0.543 & 19 \\
\hline $\mathrm{C}$ & 2 & 0.029555 & 0.014777 & 0.23 & 0.812 & 5 \\
\hline $\mathrm{D}$ & 2 & 0.009145 & 0.003567 & 0.06 & 0.947 & 2 \\
\hline $\mathrm{E}$ & 2 & 0.070228 & 0.016524 & 0.26 & 0.794 & 3 \\
\hline $\mathrm{A}^{*} \mathrm{~B}$ & 2 & 0.019045 & 0.009523 & 0.15 & 0.870 & 5 \\
\hline $\mathrm{B}{ }^{*} \mathrm{C}$ & 4 & 0.027632 & 0.006908 & 0.11 & 0.968 & 22 \\
\hline Error & 2 & 0.127340 & 0.063670 & & & 100 \\
\hline Total & 17 & 0.563146 & & & & 3 \\
\hline
\end{tabular}


TABLE III.

RESPONSE TABLE FOR MEANS

\begin{tabular}{|r|l|l|l|l|l|}
\hline Level & \multicolumn{1}{|c|}{ A } & \multicolumn{1}{|c|}{ B } & \multicolumn{1}{c|}{ C } & \multicolumn{1}{c|}{ D } & \multicolumn{1}{c|}{ E } \\
\hline 1 & 0.2601 & $0.4573^{*}$ & 0.3038 & $0.3837^{*}$ & 0.3080 \\
\hline 2 & $0.4561^{*}$ & 0.2690 & $0.4012^{*}$ & 0.3288 & 0.3202 \\
\hline 3 & - & 0.3480 & 0.3693 & 0.3618 & $0.4462^{*}$ \\
\hline Delta & 0.1960 & 0.1883 & 0.0973 & 0.0548 & 0.1382 \\
\hline Rank & 1 & 2 & 4 & 5 & 3 \\
\hline
\end{tabular}

*Optimum level

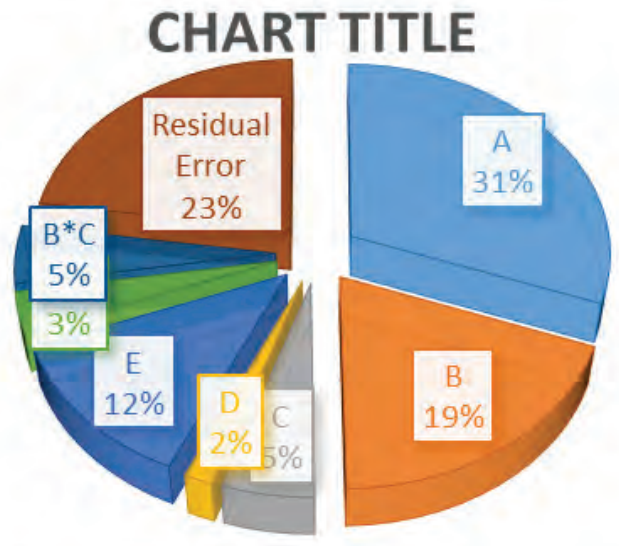

Figure $1 . \%$ of contribution of Individual parameters

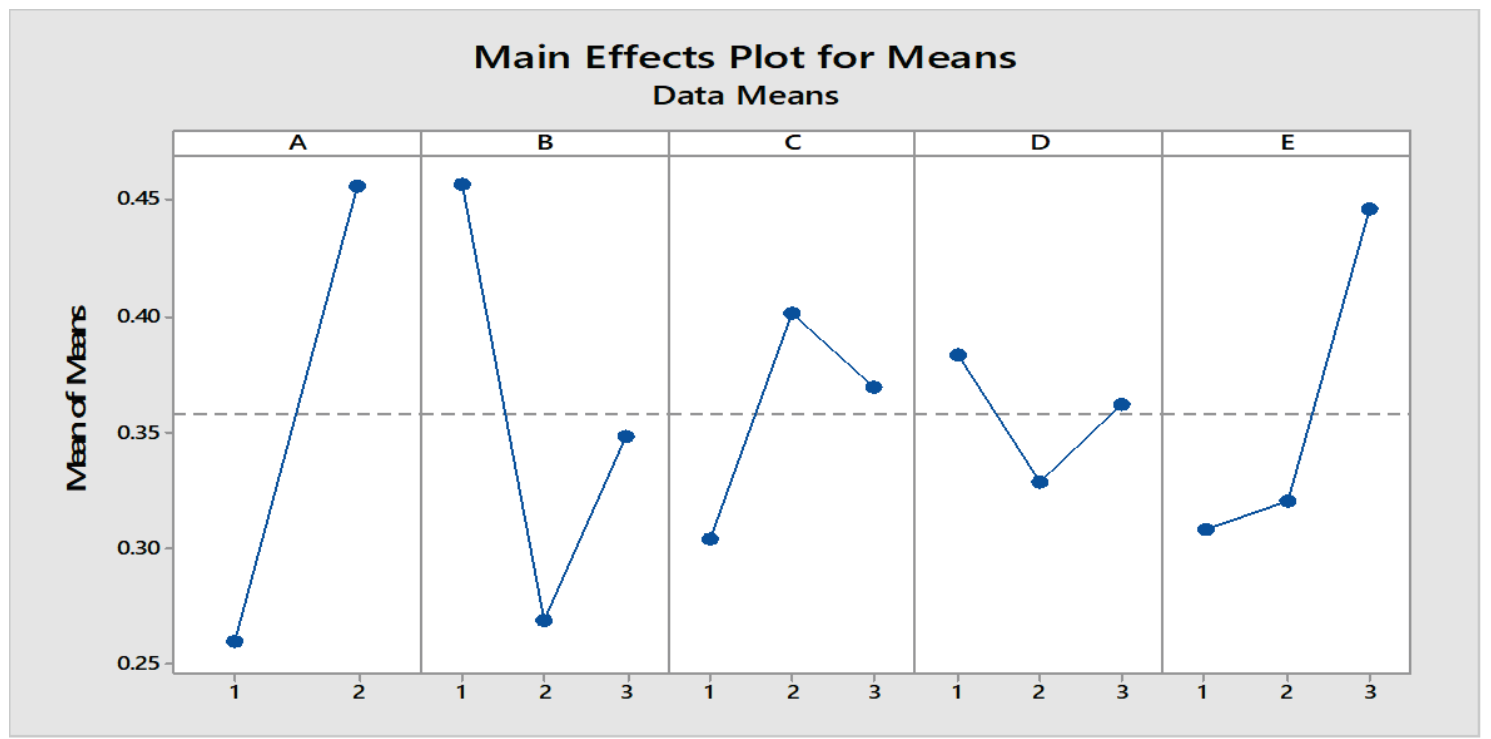

Figure 2. Main effect plot for means

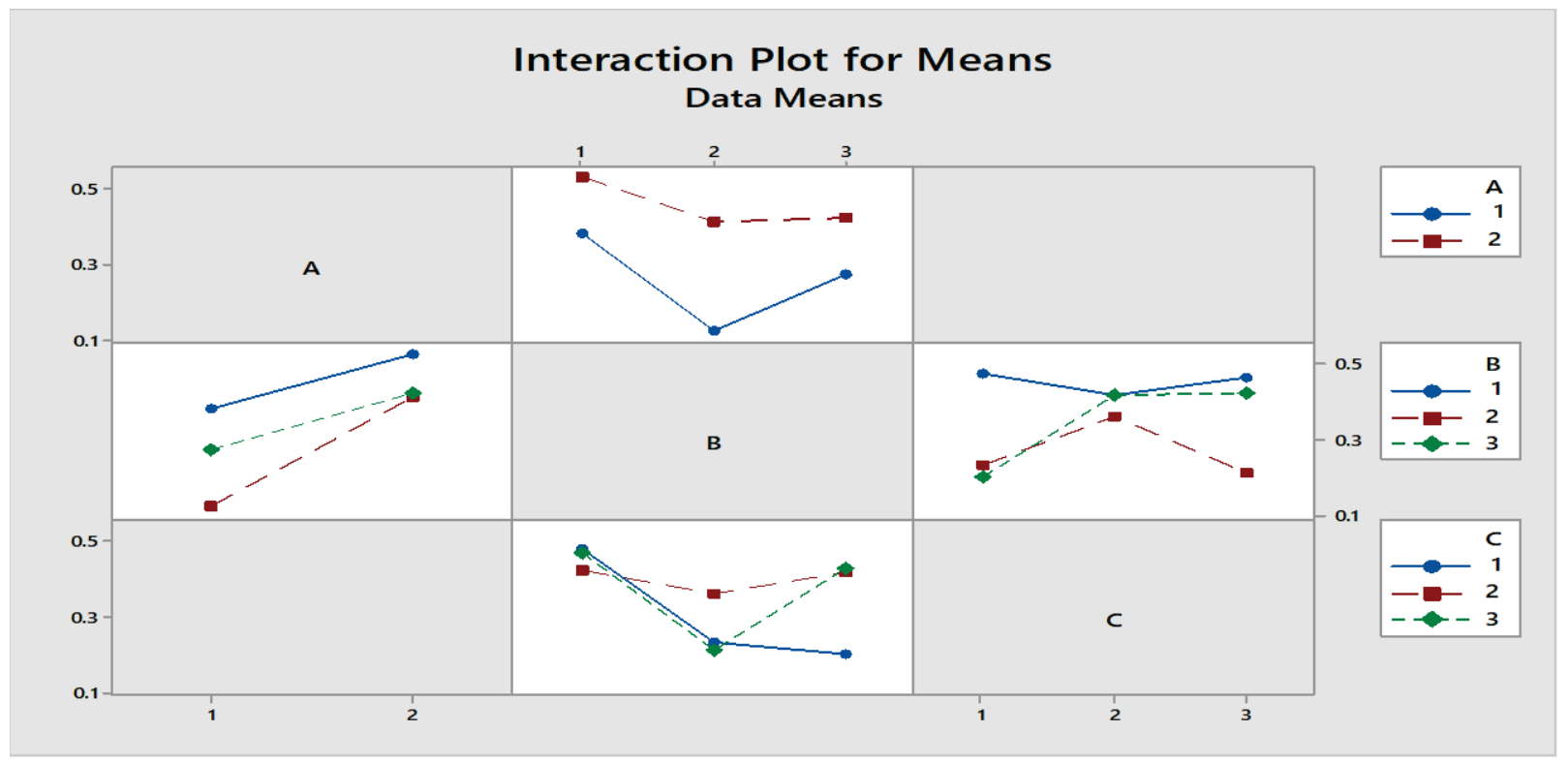

Figure 3. Interaction plot for means 
TABLE IV.

ANALYSIS OF VARIANCE FOR S/N RATIO

\begin{tabular}{|c|c|l|l|l|l|l|}
\hline Source & DF & \multicolumn{1}{|c|}{ SS } & \multicolumn{1}{|c|}{ MS } & P & of Contri bution \\
\hline A & 1 & 1569.45 & 1569.45 & 2.95 & 0.228 & 22.62443 \\
\hline B & 2 & 985.83 & 492.92 & 0.93 & 0.519 & 14.21125 \\
\hline C & 2 & 796.33 & 398.16 & 0.75 & 0.572 & 11.47951 \\
\hline D & 2 & 4.91 & 1.90 & 0.00 & 0.996 & 0.07078 \\
\hline E & 2 & 928.36 & 397.21 & 0.75 & 0.573 & 13.38279 \\
\hline A*B & 2 & 763.71 & 381.86 & 0.72 & 0.582 & 11.00927 \\
\hline B*C & 4 & 822.89 & 205.72 & 0.39 & 0.810 & 11.86238 \\
\hline Error & 2 & 1065.49 & 532.75 & & & 15.35959 \\
\hline Total & 17 & 6936.97 & & & & 100 \\
\hline
\end{tabular}

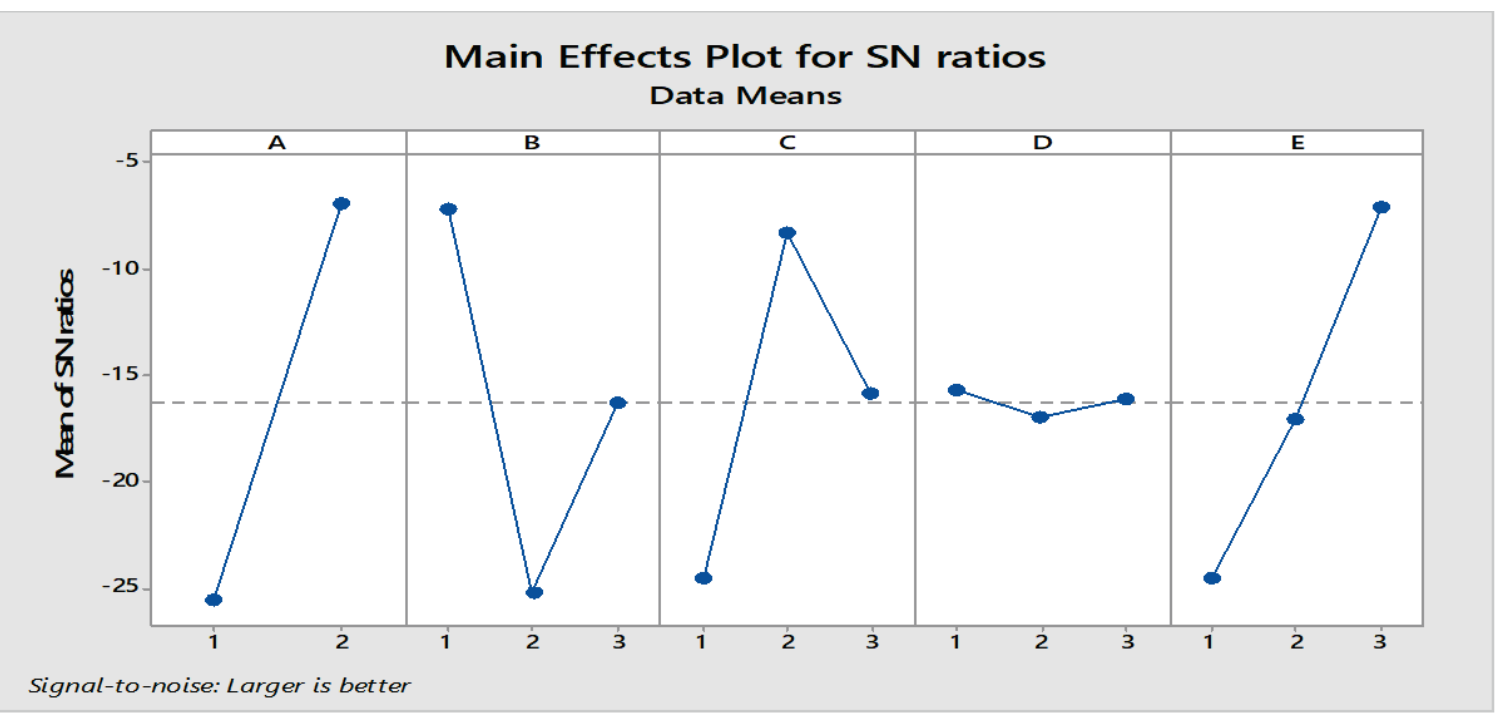

Figure 4. Main effect plot for $\mathrm{S} / \mathrm{N}$ ratio

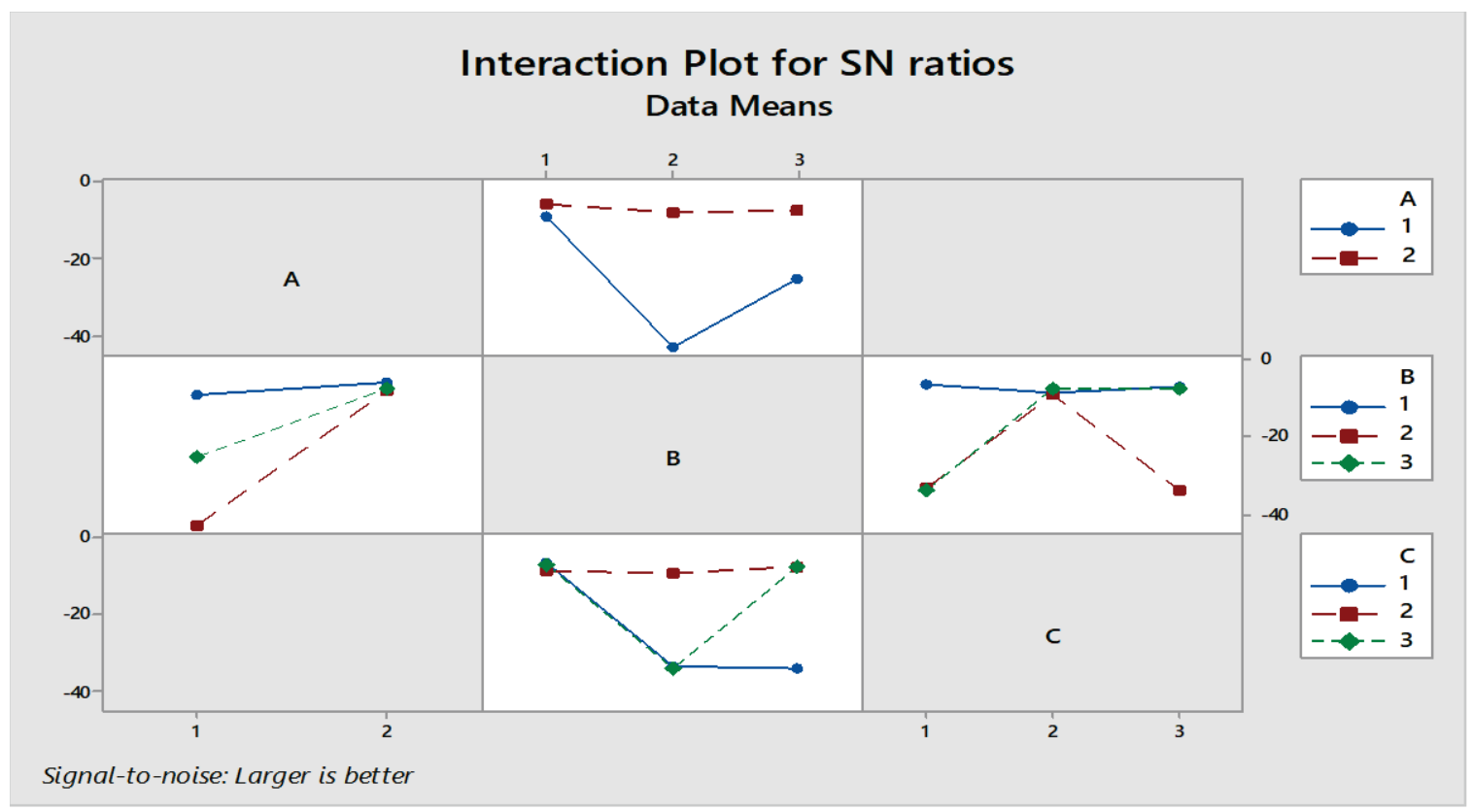

Figure 5. Interaction plot for $\mathrm{S} / \mathrm{N}$ ratio 


\section{CONCLUSIONS}

Multi-objective optimization of process parameters of the EDC process is performed using DFA and the optimum input parameters are obtained. The optimum levels are found to be Level-2 for sintering temperature, Level-1 for compaction pressure, Level-2 for discharge current, Level-1 for duty cycle and level-3 for pulse-on-time. It is found that DEA is suitable to obtain the optimum parameters during the EDC process.

\section{REFERENCES}

[1] A. K. Sahu, S. S. Mahapatra \& S. Chatterjee, "Optimization of Electro-Discharge Coating Process using Harmony Search", Materials Today: Proceedings, 5, 2018, pp. 12673-12680.

[2] P. K. Patowari, P. Saha \& P. K. Mishra, "Taguchi analysis of surface modification technique using $\mathrm{W}-\mathrm{Cu}$ powder metallurgy sintered tools in EDM and characterization of the deposited layer", Int J Adv Manuf Technol, 2011, 54, pp. 593-604.

[3] P. K. Patowari, P. Saha \& P. K. Mishra, "An experimental investigation of surface modification of C-40 steel using W$\mathrm{Cu}$ powder metallurgy sintered compact tools in EDM", Int $\mathrm{J}$ Adv Manuf Technol, 2015, 80, pp.343-360, DOI 10.1007/s00170-015-7004-7.

[4] A. Ahmed, "Deposition and Analysis of Composite Coating on Aluminum Using Ti-B4C Powder Metallurgy Tools in EDM", Materials and Manufacturing Processes, 2014, 31:4, pp. 467-474, DOI: 10.1080/10426914.2015.1025967.
[5] A. K. Sahu \& S. S. Mahapatra, "Electrical Discharge Coating by Copper-Tungsten Composite Electrode Prepared by Powder Metallurgy Route", Soft Computing Techniques and Applications in Mechanical Engineering. 2018, DOI: 10.4018/978-1-5225-3035-0.ch010.

[6] S. K. Sahoo, S. S. Naik and J. Rana (2019), Experimental Analysis of Wire EDM Process Parameters for Micromachining of High Carbon High Chromium Steel by Using MOORA Technique, In Micro and Nano Machining of Engineering Materials, Materials Forming, Machining and Tribology, Springer, https://doi.org/10.1007/978-3-31999900-5_7.

[7] A. Bara, S. K. Sahoo, S. S. Naik, A. K. Sahu and S. S. Mahapatra (2018), Multi-Response Optimization of Nd: YAG Laser Micro Drilling Characteristics of 304 Stainless Steel using Desirability Function Approach, Materials Today: Proceedings, 5,18975-18982.

[8] A. K. Sahu \& S. S. Mahapatra, "Optimization of Surface Roughness Parameters by Different Multi-Response Optimization Techniques During Electro-Discharge Machining of Titanium Alloy", Chapter 4, Optimization of Surface Roughness Parameters, Non-Conventional Machining in Modern Manufacturing Systems. 2019, DOI: 10.4018/9781-5225-6161-3.ch004.

[9] P. Karande , S. K. Gauri \& S. Chakraborty, "Applications of utility concept and desirability function for materials selection" Materials and Design, 45, 2013, pp. 349-358.

[10] B. Singaravel \& T. Selvaraj, "Application of Desirability Function Analysis and Utility Concept for Selection of Optimum Cutting Parameters in Turning Operation", Journal of Advanced Manufacturing Systems, Vol. 15, No. 1, 2016, pp. 1-11. 